\title{
Low-Intensity Pulsed Ultrasound Accelerates Osteoblast Differentiation and Promotes Bone Formation in an Osteoporosis Rat Model
}

\author{
Shuliang $\mathrm{Wu}^{\mathrm{a}}$ Yumi Kawahara $^{\mathrm{a}, \mathrm{b}}$ Tomotaka Manabe $^{\mathrm{a}}$ Kazuyuki Ogawa $^{\mathrm{a}}$ \\ Masaya Matsumoto ${ }^{a}$ Akira Sasaki $^{a}$ Louis Yuge ${ }^{a, b}$ \\ a Division of Bio-Environmental Adaptation Sciences, Graduate School of Health Sciences, and \\ ${ }^{b}$ Space Bio-Laboratories Y.K., Hiroshima University, Hiroshima, Japan
}

\section{Key Words}

Core-binding factor A1 - Low-intensity pulsed ultrasound •

Normal human osteoblasts · Osteoporosis · Ovariectomy

\begin{abstract}
Objective: We examined the effects of low-intensity pulsed ultrasound (LIPUS) on cell differentiation, bone mineralized nodule formation and core-binding factor $\mathrm{A} 1$ (Cbfa1) expression in a normal human osteoblast (NHOst) cell line and bone formation in an osteoporosis animal model. Methods: $\mathrm{NHOst}$ cells were cultured in vitro in medium with or without LIPUS stimulation. The ultrasound stimulation frequency was $1.0 \mathrm{MHz}$ at an intensity of $30 \mathrm{~mW} / \mathrm{cm}^{2}$ for $20 \mathrm{~min}$. Rats were divided into a sham-operated group (Sham) and an ovariectomized group (OVX). The right femur was treated with LIPUS (Sham-LIPUS and OVX-LIPUS) and the left femur was left untreated (Sham-CON and OVX-CON). Results: LIPUS stimulation accelerated bone nodule formation and enhanced alkaline phosphatase activity. The expression levels of $\mathrm{Cbfa} 1$ decreased and calcification occurred earlier and more frequently in the LIPUS than in the CON groups. The wet weight of the femur increased in OVX rats with LIPUS stimulation. Morphological images showed an increase in trabecular spongiosa in the OVX-LIPUS group. Conclusion:
\end{abstract}

LIPUS accelerated osteogenesis. Moreover, since LIPUS prevents bone loss, it may be a promising treatment for osteoporosis.

Copyright $\odot 2009$ S. Karger AG, Basel

\section{Introduction}

Osteoporosis is the most common bone disorder found in elderly women. Its etiologies include aging, sedentary lifestyle and estrogen deficiency due to menopause, ovariectomy and hormonal therapy [1-3]. Particularly estrogen deficiency leads to rapid and marked loss of bone mineral content [4].

Low-intensity pulsed ultrasound (LIPUS) is a pressure or sound wave with the capability to transfer mechanical energy into biological tissues [5]. This acoustic energy promotes bone formation in both animals and humans with osteoporosis [6-8]. Numerous in vivo animal studies and prospective, double-blind, placebo controlled, clinical trials have shown that LIPUS is capable of accelerating and augmenting the healing of osteoporosis [9].

Accelerated healing of osteoporosis by LIPUS is attributed to the production of pressure waves, which in- 
duce biochemical and molecular events at the cellular level [10]. However, the mechanotransduction pathways through which LIPUS stimulates living tissues are still not completely understood. Ott [11] showed that the ultrasound-stimulated proximal portion of the femurs of 6 patients with spinal cord injury had more bone mass than the non-stimulated one. On the contrary, Warden et al. [12] reported that 12-week LIPUS stimulation had no effect on bone mass in ovariectomized rats. Fifteen patients with spinal cord injury treated with LIPUS for 6 weeks on their calcanei continued to have decreases in bone mass similar to the non-treated patients [13].

LIPUS has been found to induce differentiation in long-bone-derived osteoblasts of adult rats in vitro [14]. It has also been reported to increase calcium accumulation in the mouse osteoblastic cell line MC3T3-E1 [15]. Even though the energy used by LIPUS is extremely low, the effects are evident. LIPUS treatment has led to increased transforming growth factor- $\beta_{1}$ mRNA expression and aggrecan synthesis in chondrocytes [16]. Histological studies suggest that LIPUS influences all major cell types involved in bone healing, including osteoblasts, osteoclasts, chondrocytes and mesenchymal stem cells [17].

Although accelerated mineralization has been associated with increases in osteocalcin, alkaline phosphatase (ALP), vascular endothelial growth factor and matrix metalloproteinase-13 expression [18] in vitro, we found no reports concerning the effect of LIPUS on an osteoporosis model in both in vivo and in vitro conditions. Therefore, we investigated the effects of LIPUS on cell differentiation, mineralized nodule formation and corebinding factor A1 (Cbfa1) expression in a normal human osteoblast (NHOst) cell line. We also analyzed the effect of LIPUS stimulation on osteoporosis using an ovariectomized osteoporosis rat model. We hypothesize that LIPUS stimulation prevents bone loss.

\section{Materials and Methods}

\section{Cell Culture}

NHOst cells were purchased from BioWhittaker (Walkersville, Md., USA). The cells were seeded in $60-\mathrm{mm}$ culture dishes (Nalge Nunc International, Roskilde, Denmark) and maintained in osteoblast proliferation medium, which contained osteoblast basal medium $\left(\mathrm{OBM}^{\circledR}, \mathrm{CC}-3208\right.$; BioWhittaker) with $10 \%$ fetal bovine serum (CC-4102), $200 \mathrm{nM}$ ascorbic acid (CC-4398) and $200 \mathrm{nM}$ gentamicin/amphotericin-B (CC-4381).

An osteoblast differentiation medium, which consisted of OBM supplemented with Single Quots ${ }^{\circledR}$ containing $200 \mathrm{nM}$ hydrocortisone, $10 \mathrm{mM} \beta$-glycerophosphate and $10 \mu \mathrm{M}$ 1,25-dihydroxyvitamin $\mathrm{D}_{3}$ (Calbiochem, La Jolla, Calif., USA), was used for the NHOst cell differentiation experiment. The cells were transferred to osteoblast differentiation medium and their concentration was adjusted to $1.2 \times 10^{4}$ cells $/ \mathrm{mm}^{3}$ using a hemocytometer (Erma, Tokyo, Japan). The cells were then seeded in 60-mm polymeric membrane culture dishes (day 0 of culture; BD Bioscience, Bedford, Mass., USA) and cultured for 21 days at $37^{\circ} \mathrm{C}$ in a humidified atmosphere of $95 \%$ air and $5 \% \mathrm{CO}_{2}$. The medium was replaced twice weekly.

\section{Animals}

Twenty-seven Wistar rats (female, 16 weeks old, $246.1 \pm$ $13.8 \mathrm{~g}$ ) were used. The animals were housed under standard laboratory conditions on a 12-hour light/dark cycle and at a temperature of $23 \pm 1{ }^{\circ} \mathrm{C}$ and relative humidity of $55 \pm 5 \%$. The rats were divided into a sham-operated group (Sham, $\mathrm{n}=12$ ) and an ovariectomized group (OVX, $\mathrm{n}=15)$. The experimental protocol was approved by the Animal Care and Use Committee of Hiroshima University.

\section{In vitro and in vivo LIPUS}

The NHOst cells were seeded in a polymeric membrane culture dish, the bottom of which was thin enough to transmit the ultrasound signal. The membranes of the specially constructed dishes were made of biocompatible, polyether-based thermoplastic polyurethane to facilitate the transmission of ultrasound. The method of ultrasound stimulation was similar to that described by Sena et al. [19]. In brief, the cells were divided into two groups. In the LIPUS group, the ultrasound stimulus (LIPUS; Sonic Accelerated Fracture Healing System; Teijin, Osaka, Japan) was administered through a thin silicone pad to the bottom of the culture plates. The ultrasound stimulation frequency was $1.0 \mathrm{MHz}$ at an intensity of $30 \mathrm{~mW} / \mathrm{cm}^{2}$. The osteoblasts were exposed to ultrasound for $20 \mathrm{~min}$ on days $1,3,5,7,10,12,14,18$ and 21 of culture. In the control group, cells were seeded and cultured in the same manner as in the LIPUS group, but did not receive ultrasound stimulation.

One week after ovariectomy or the sham operation, rats were anesthetized with diethyl ether and the proximal portion of their right femurs was prepared to receive LIPUS (OVX-LIPUS), whereas the left femurs were left untreated (OVX-CON). The sham-operated animals were similarly grouped and treated (Sham-LIPUS and Sham-CON). The ultrasound stimulation frequency was the same as that used before. We performed the experiment for 20 $\mathrm{min} /$ day, 5 times/week for 5 weeks.

Assessment of Mineralized Nodule Formation in NHOst Cells

The NHOst cells, with or without LIPUS stimulation, were collected after $1,3,5,7,10,12,14,18$ and 21 days of culture. The presence of mineralized nodules was confirmed with von Kossa silver nitrate staining (Wako, Osaka, Japan) as described by Park et al. [20]. In brief, cells were rinsed with phosphate-buffered saline and fixed in $4 \%(\mathrm{w} / \mathrm{v})$ paraformaldehyde in phosphate-buffered saline for $10 \mathrm{~min}$. After washing with distilled water, cells were stained with $5 \%(\mathrm{w} / \mathrm{v})$ silver nitrate solution and kept in the dark for $30 \mathrm{~min}$. The cells were washed with distilled water to remove excess silver nitrate, and the culture plate was treated for several minutes with sodium carbonate/formaldehyde solution to develop color. Residual silver nitrate was neutralized with $5 \%$ sodium thiosulfate. 


\section{ALP Staining}

The NHOst cells were rinsed three times with calcium and phosphate-free saline, fixed in $4 \%$ paraformaldehyde for $15 \mathrm{~min}$ at room temperature, washed three times with double-distilled water and stained with 5-bromo-4-chloro-3-indolyl phosphate/ nitroblue tetrazolium/ALP substrate (Amresco, Solon, Ohio, USA) for $15 \mathrm{~min}$ at room temperature. The cells were then washed with distilled water.

\section{Reverse Transcription-Polymerase Chain Reaction}

Total RNA of the cells was obtained using ISOGEN reagent (Nippon Gene, Tokyo, Japan). For reverse transcription, we used SuperScript II (Invitrogen, Carlsbad, Calif., USA). Sense and antisense primers for Cbfal and glyceraldehyde-3-phosphate dehydrogenase (GAPDH, internal control) were: Cbfal, sense $5^{\prime}$ CCG ATG GGA CCG TGG TTA-3' and antisense 5'-GCG CCC TAA ATC ACT GAG G-3'; GAPDH, sense 5'-TCTTCACCACCATGGAGAAGGCTG-3' and antisense ${ }^{\prime}$ '-ACAGTCTTCTGAGTGGCAGTGATG-3'. The expected size of the polymerase chain reaction (PCR) products was $308 \mathrm{bp}$ for Cbfal and $262 \mathrm{bp}$ for GAPDH. Cbfa1 PCR conditions were 35 cycles for $1 \mathrm{~min}$ at $94^{\circ} \mathrm{C}, 1 \mathrm{~min}$ at $60^{\circ} \mathrm{C}$ and $1 \mathrm{~min}$ at $72^{\circ} \mathrm{C}$. PCR conditions for GAPDH amplification were 24 cycles at the same temperatures and durations. The images were processed with a computer-assisted scanner and band density was analyzed using NIH Image v1.62 FPU software (National Institutes of Health, Bethesda, Md., USA).

\section{Uterus and Femur Analysis}

After 1, 3 and 5 weeks of LIPUS stimulation, the uteri and femurs were removed from rats anesthetized with excess pentobarbital. In the four treatment groups (OVX-LIPUS, OVX-CON, Sham-OVX and Sham-CON), the wet weights of uteri and both femurs were determined to investigate the effects of ovariectomy, and the femur weight/body weight ratio was calculated. LIPUS efficiency was determined by dividing femur weight in the LIPUS group by femur weight in the CON group. Radiographs were taken using micro-focus X-ray magnification equipment (micro FX1000; FUJIFILM, Tokyo, Japan) to measure the increase in photostimulated luminescence (per $\mathrm{mm}^{2}$ ) using Image Gauge software (FUJIFILM)

\section{Femur Morphology}

One third of the proximal portions of the right and left femurs was embedded in paraffin, degreased with ethanol and demineralized for 2 weeks with 3\% EDTA. Each sample was washed, dehydrated, filled with paraffin, sliced into $5-\mu \mathrm{m}$ segments and stained with hematoxylin-eosin using the paraffin sectioning method.

\section{Statistical Analysis}

Results are expressed as means \pm SD. Intergroup differences were compared by one-way analysis of variance followed by the post hoc test using StatView version 5.0 software (SAS Institute, Cary, N.C., USA), and $\mathrm{p}<0.05$ was considered statistically significant.

\section{Results}

Influence of LIPUS on Mineralized Nodule Formation in NHOst Cells

After 21 days of culture, mineralized nodules formed with or without LIPUS stimulation (fig. 1). However, the stages of nodule formation clearly differed between the control and ultrasound-treated cultures. In the LIPUS treatment group, the cells went through progressive stages of proliferation and early differentiation during days $0-3$; matrix deposition and early nodule formation during days 3-7, and matrix mineralization during days 721 . In the control group, proliferation and early differentiation occurred during days $0-5$; matrix deposition and early nodule formation during days $5-10$, and matrix mineralization during days $10-21$.

To qualitatively and quantitatively assess mineralized matrix formation, NHOst cells were stained with von Kossa silver nitrate on days 1, 3, 5, 7, 10, 12, 14, 18 and 21. LIPUS treatment significantly altered the stages and extent of mineralized nodule formation (fig. 2, 3). By day 12, the population of mineralized cells had significantly increased with LIPUS stimulation ( $p<0.05$, fig. 2 ), and compared to control cells, the nodules in LIPUS-stimulated NHOst cells showed increased von Kossa silver nitrate staining (fig. 3).

\section{Influence of LIPUS on ALP Activity}

ALP activity was significantly greater in the LIPUS group on days 3, 5, 7 and 10 (fig. 3), but there was no difference in its activity after day 10 (data not shown).

\section{Analysis of Uteri and Femurs}

The wet weight of the uteri was significantly less in the OVX group than in the Sham group after 3 and 5 weeks (fig. 4), and that of the femurs in the OVX group was less than that in the Sham group (fig. 5a); however, the wet weight of the stimulated (right) femurs was similar to the control (left) femurs after 3 weeks of LIPUS stimulation. There was no effect of LIPUS stimulation in the ShamLIPUS group. The increase in the rate of femur weight gain (expressed as LIPUS femur weight/CON femur weight) was enhanced by LIPUS (fig. 5b).

$\mathrm{X}$-ray films showed high X-ray transmittance around the femoral neck and loss of bone mineral content in the OVX group, but there were no significant changes between OVX-LIPUS and OVX-CON groups (fig. 6). Similarly, there were no changes in the photostimulated luminescence per square millimeter of femur (table 1). 
Fig. 1. LIPUS treatment accelerated bone nodule formation in cultured NHOst cells. White arrow indicates an island-like colony formation. Black arrow indicates a bone nodule. Scale bar $=100 \mu \mathrm{m}$.

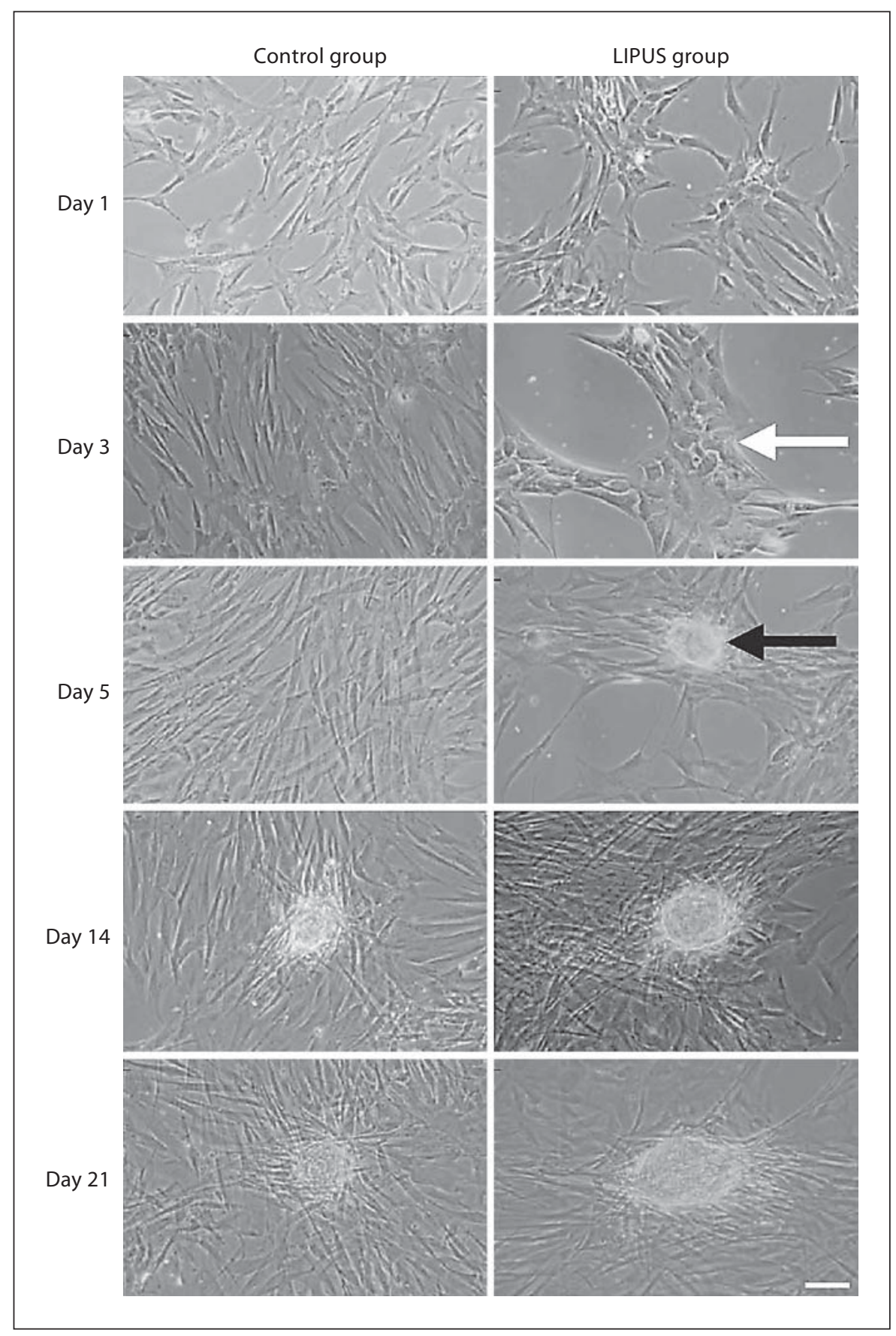

\section{Morphological Changes in Femurs}

Trabecular spongiosa was detected by light microscopy in the femur specimens. In the OVX group, there was a decrease in trabecular spongiosa in both right and left femurs. After 3 and 5 weeks of LIPUS stimulation, density and disruption of trabecular spongiosa were decreased in the OVX-CON group. In contrast, the density and continuity in the OVX-LIPUS group was good (fig. 7). In the Sham group, trabecular spongiosa continuity was maintained irrespective of LIPUS stimulation. Although there was no change between the OVX-LIPUS and OVXCON groups after 1 and 3 weeks of stimulation, trabecular spongiosa tended to increase in the Sham-LIPUS group after 5 weeks of stimulation (fig. 7). 


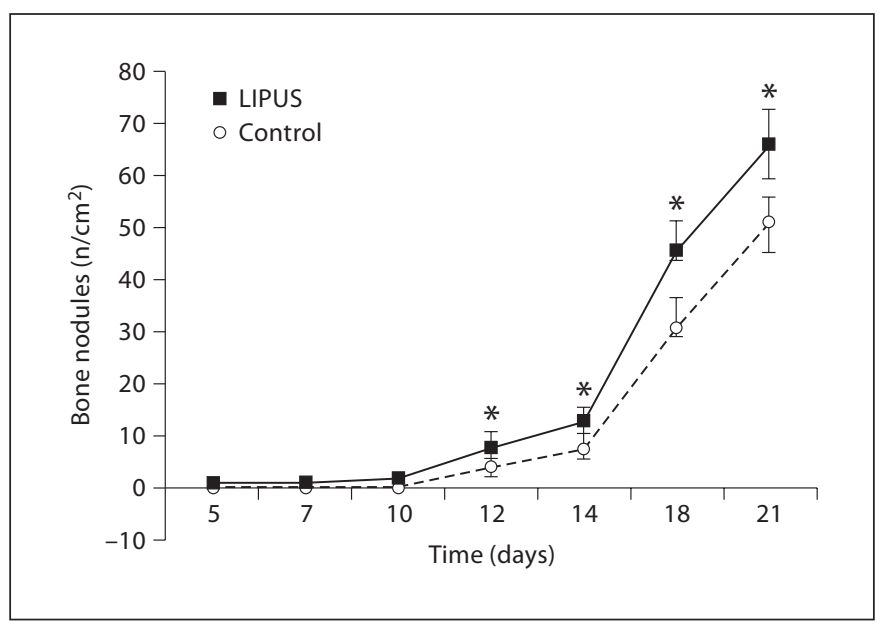

Fig. 2. LIPUS treatment increased bone nodule formation in cultured NHOst cells. Data are means \pm SD for triplicate samples in three separate experiments. ${ }^{*} \mathrm{p}<0.05$ vs. the control group.

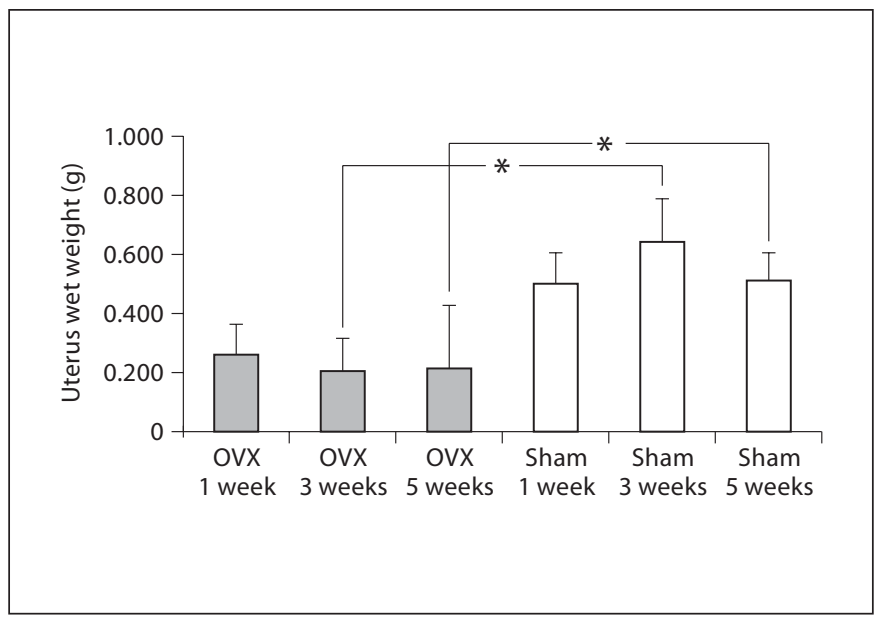

Fig. 4. The uterus wet weight was significantly lower in the OVX group compared to the Sham group. Means \pm SD. ${ }^{*} \mathrm{p}<0.05$.

Fig. 3. LIPUS treatment increased ALP expression and mineralization. Cells were cultured in osteoblast differentiation medium for up to 7 days with or without LIPUS treatment. Cells were double stained with ALP substrate and von Kossa silver nitrate stain (mineralization). Grey = ALPpositive cells; black $=$ mineralized deposits. Scale bar $=100 \mu \mathrm{m}$.
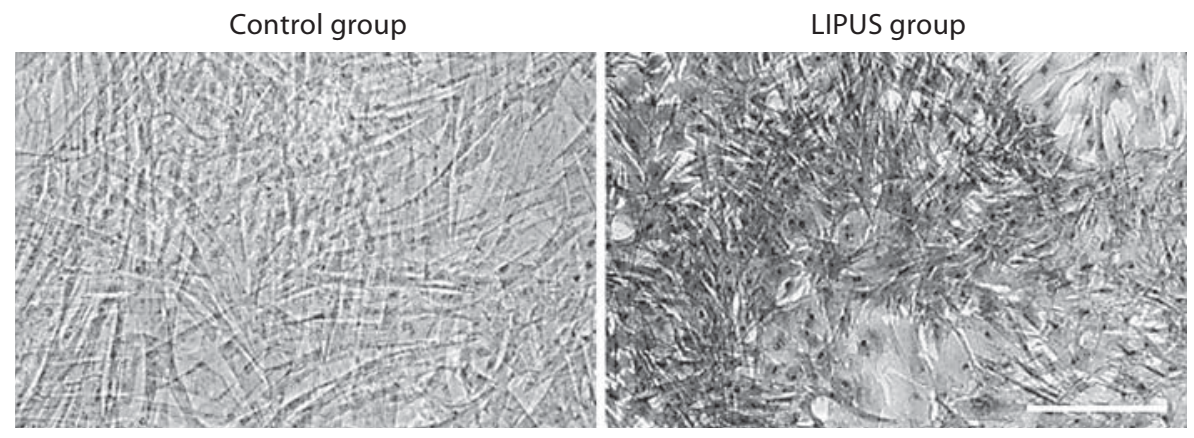

\section{Cbfa1 mRNA Expression}

In LIPUS-stimulated femurs of the OVX group, Cbfal expression was slight but detectable, while it was strong in non-stimulated femurs. In the Sham group, Cbfal expression remained high in stimulated femurs, but was lower in non-stimulated ones (fig. 8). There was greater variability in Cbfal expression in the non-stimulated than the stimulated side in both groups.

\section{Discussion}

In previous studies, cells were plated in normal culture dishes and LIPUS stimulation was directed at the bottom of the dishes. However, given the acoustic dose, the functional properties of LIPUS stimulation may have changed and the shape of the LIPUS beam may have been altered.
In this study, we used a novel LIPUS treatment system that enables more controlled experimental conditions.

The formation of a mineralized matrix is a definitive hallmark of osteoblastic differentiation [21,22]. To determine whether LIPUS treatment had an effect on NHOst cell differentiation, we examined mineralized nodule formation by phase-contrast microscopy and von Kossa silver nitrate staining [23]. Our results suggested that LIPUS treatment accelerated NHOst cell differentiation by increasing mineralization.

ALP activity is an early marker of osteoblast differentiation and is critical for inducing mineralization [24]. Previous studies indicated that ALP activity is initiated during the early stages of osteoblast differentiation and continues to increase until the mineralization stage [25]. In our experiment, LIPUS stimulation induced an increase in ALP activity in early cultures (before day 10), 


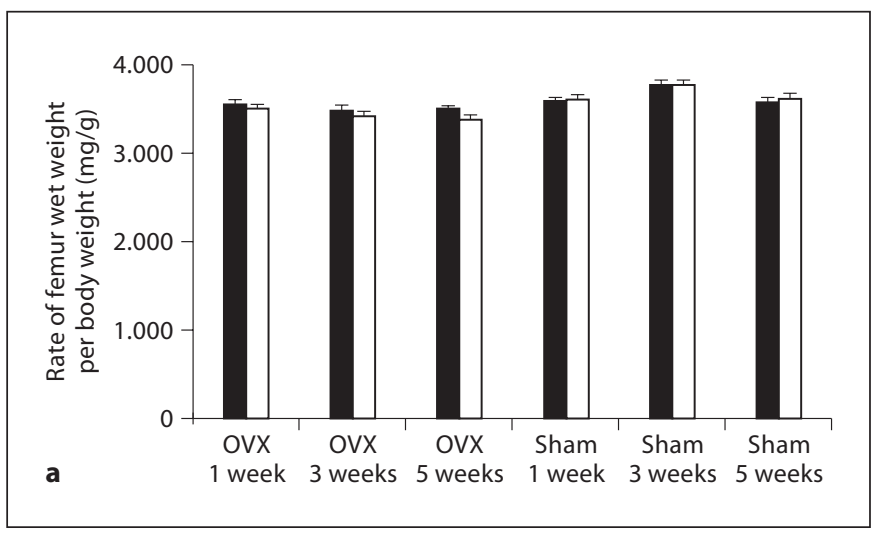

Fig. 5. a The rate of femur wet weight gain per body weight (mg/g). - = Right femur (LIPUS); $\square=$ left femur (CON). There was no difference between the OVX and Sham groups with/without LIPUS. $\mathbf{b}$ Increase in the rate of femur weight gain by LIPUS (ex-

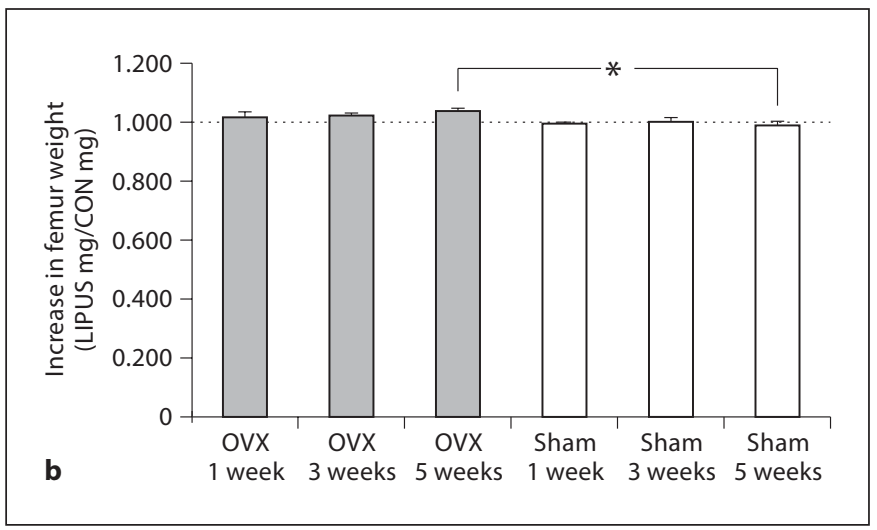

pressed as LIPUS femur weight/CON femur weight). The weight gain was significantly higher in the OVX group than in the Sham group after 5 weeks of stimulation. Means \pm SD. ${ }^{*} \mathrm{p}<0.05$.

Table 1. Rate of increase in photostimulated luminescence (PSL) per $\mathrm{mm}^{2}$ of femur

$\mathrm{PSL} / \mathrm{mm}^{2}$ (LIPUS/CON)

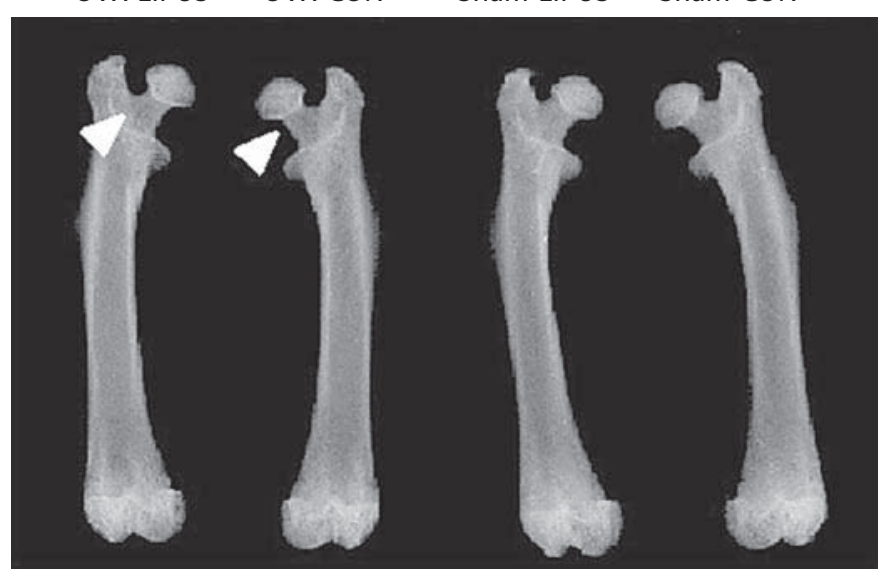

Fig. 6. LIPUS treatment decreased the loss of bone mineral content. Bone mineral content was analyzed by X-ray. X-ray transmittance around the femoral neck was higher in the OVX group (OVX-LIPUS and OVX-CON) than in the Sham group (ShamLIPUS and Sham-CON).

but after day 10 the increase was not significant, indicating that LIPUS affects the early stages of osteoblast differentiation by increasing ALP activity.

The uterus wet weight decreased in the OVX group (fig. 4). It is known that the uterus atrophies are due to the lack of estrogen stimulation within 2-3 days following ovariectomy [26], indicating that the 1-week delay we allowed prior to experimentation was sufficient to remove the estrogen effect. Ovarian hypofunction was confirmed more than 2 weeks after surgery. Because there were only slight differences in the progression of bone atrophy and minimal bone mineral loss during the 5 -week experiments, we could not detect a significant change in bone mineral content. Warden et al. [27] reported no difference in bone mineral content and density in a rat model of osteoporosis despite 12 weeks of LIPUS stimulation. Thus, the conversion in bone may be so low that it cannot be discriminated by X-ray. In our opinion, long-term studies investigating changes in bone mineral content and density are required to elucidate the effects of LIPUS on bone atrophy.

The bone-specific Cbfa1 gene is a runt-domain-containing transcription factor essential for osteoblastic differentiation and bone formation during embryogenesis and postnatal life [28]. We considered Cbfal to have two functions: (1) promotion of the initial phase of differentiation from mesenchymal stem cells to pre-osteoblasts 


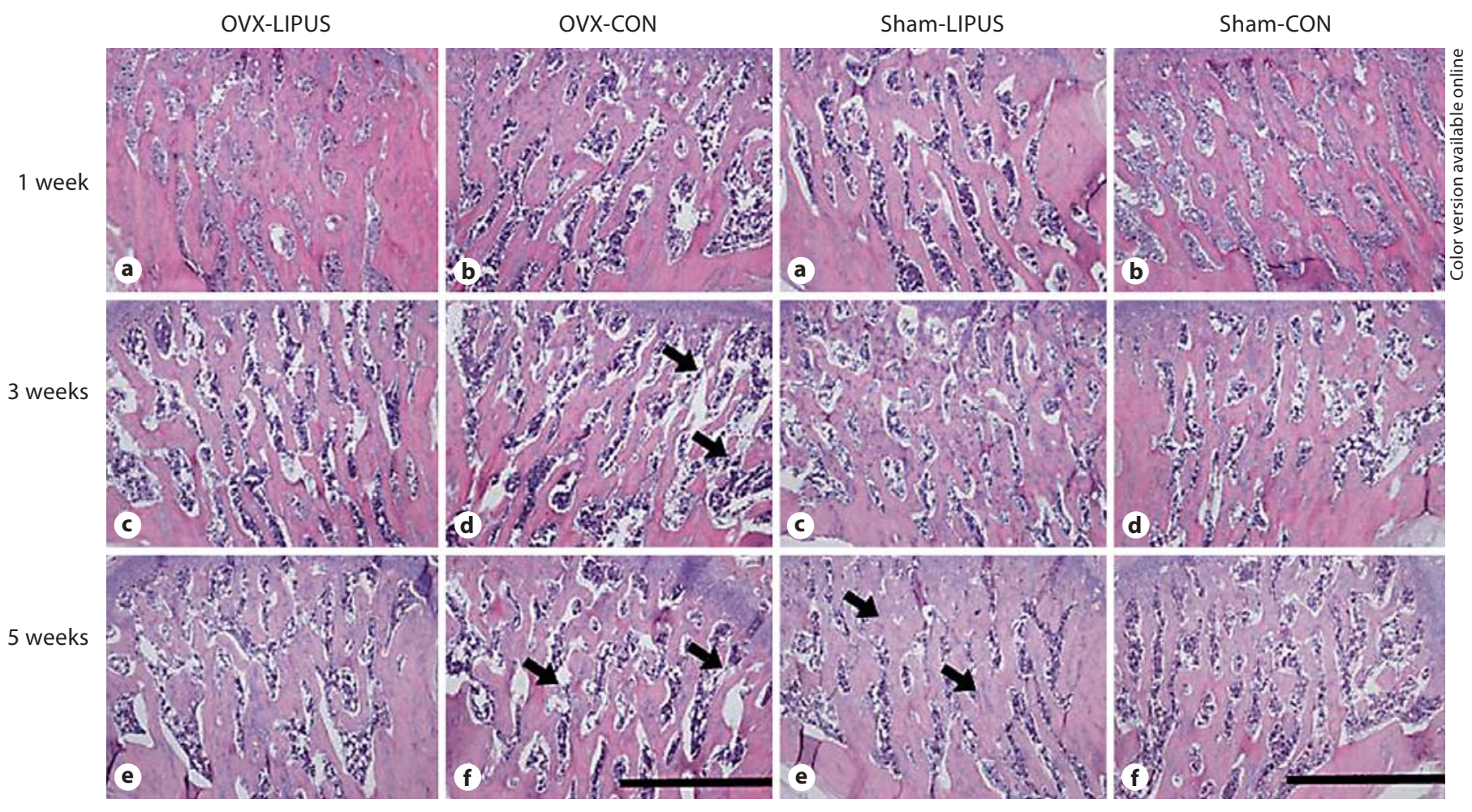

Fig. 7. LIPUS treatment affected bone morphology. The morphology of bone longitudinal sections at the proximal portion of femurs was examined by hematoxylin-eosin staining. In the OVX group, trabecular spongiosa clearly diminished from 1 to 3 weeks irrespective of LIPUS stimulation $(\mathbf{a}, \mathbf{c} / \mathbf{b}, \mathbf{d})$. In the OVX-CON group, trabecular spongiosa disappeared or was disrupted $(\mathbf{d}, \mathbf{f}), \quad 2 \mathrm{~mm}$.

but there was good density and continuity in the OVX-LIPUS group (c, e). In the Sham group, the trabecular continuity was maintained. There was no effect of LIPUS after 1 and 3 weeks (a, $\mathbf{c} / \mathbf{b}, \mathbf{d})$. After 5 weeks, the trabeculae were stronger in the ShamLIPUS group than in the Sham-CON group $(\mathbf{e}, \mathbf{f})$. Scale bar $=$

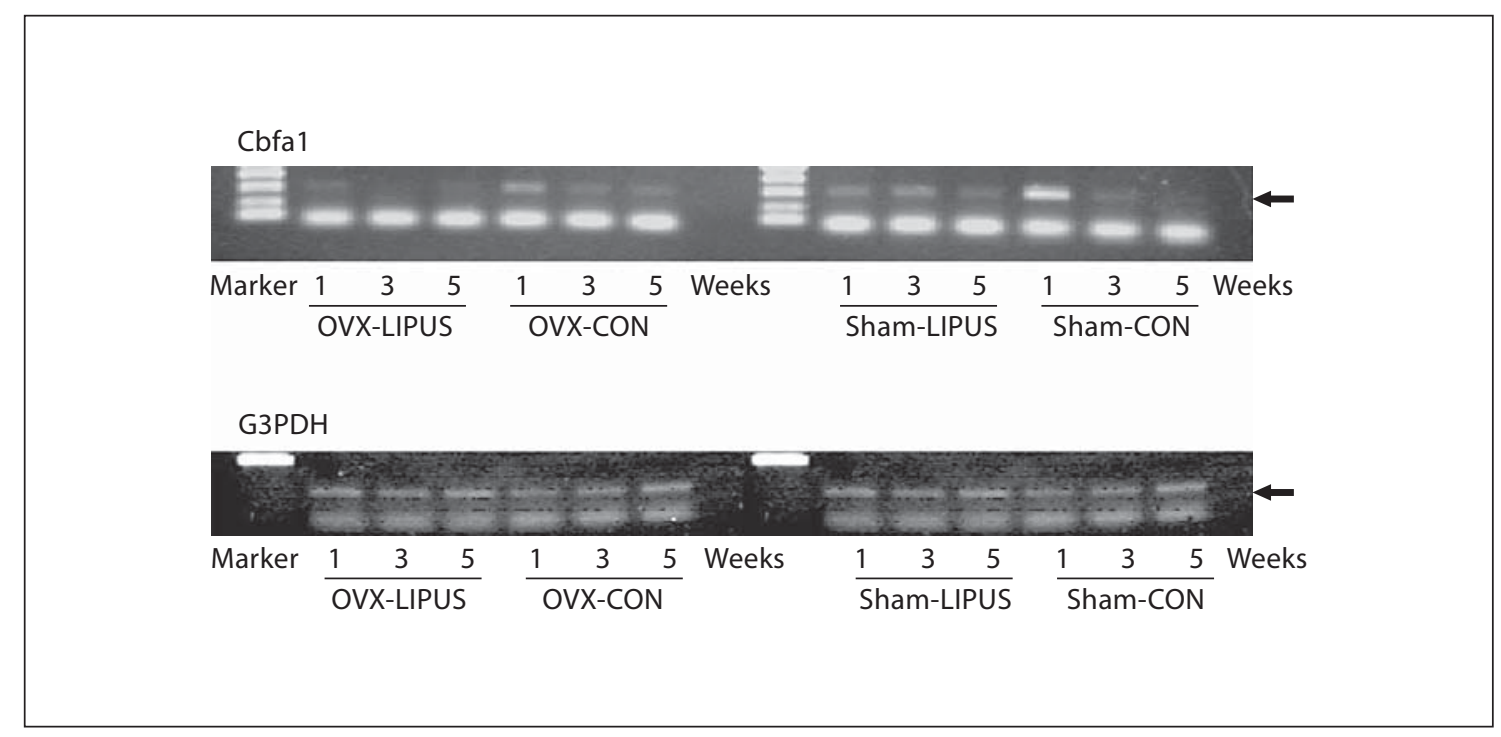

Fig. 8. Cbfa1 mRNA expression (308 bp) was lower in the OVX-LIPUS group than in the OVX-CON group. 
and (2) inhibition of pre-osteoblast differentiation to mature osteoblasts [29]. Thus, the reduced Cbfa1 mRNA expression in the OVX-LIPUS group after 3 and 5 weeks of stimulation indicated a relative acceleration of osteoblast development, which would subsequently increase the number of mature cells. This reduction in Cbfal expression resulted in an increase in bone matrix and mineral deposition onto the spongiosa surface strengthening the trabecular architecture, as indicated by the histology of the proximal portion of the femur in the OVX-LIPUS group. Accordingly, the wet weight of the bone was maintained resulting in an increased rate of wet weight gain by LIPUS stimulation. These results suggested that LIPUS-induced osteoblast maturation exceeded osteoblast proliferation in the OVX group.

Our study indicates that LIPUS stimulation alters Cbfal mRNA expression and promotes bone matrix production. Bone development and repair respond to mechanical stress, the so-called Wolff's law [30]. Ultrasound transmits high-frequency sound waves through the body that produce mechanical stress, which in turn results in a variety of cell responses. Ultrasound has been regarded as one of the most effective mechanical stressors for bone formation. Recently, very-low-intensity ultrasound stimulation, similar to LIPUS, has been clinically applied to determine its usability to treat fractures [31]. Ultrasound vibration works directly on cells with mechanoreceptors such as bone cells, osteoblasts and chondrocytes [32, 33]. These cells respond to contraction and stimulation via stretch-activated cation channels in the cell membrane that increase intracellular calcium concentrations [34] and initiate a signaling cascade [35-37].

The effects of mechanical stress on bone remodeling using an osteoporosis model have also been reported. Oxlund et al. [38] and Flieger et al. [39] suggested that low-intensity, high-frequency vibration inhibits lowerlimb bone loss. However, the rats in their studies were investigated under weight-bearing conditions, making it difficult to evaluate the independent effect of vibration. Possibly, the amplitude and velocity of the mechanical stress as well as the mechanical load act synergistically to maintain bone density. We suggest that ultrasound therapy with smaller and continuous mechanical stress, such as LIPUS, is more useful in preventing bone loss in a clinical setting.

\section{Acknowledgments}

We thank A. Okubo and Y. Kinugawa for their technical support. This work was supported by Grants-in-Aid for Scientific Research (Nos. 10838021 and 12832032 to L.Y.) from the Ministry of Education, Science, Sports, Culture and Technology of Japan.

\section{References}

1 Lewiecki EM: Prevention and treatment of postmenopausal osteoporosis. Obstet Gynecol Clin North Am 2008;35:301-315.

2 Pouilles JM, Tremollieres F, Ribot C: Effect of menopause on femoral and vertebral bone loss. J Bone Miner Res 1995;10:1531-1536.

-3 Melton LJ, Chrischilles EA, Cooper C, Lane AW, Riggs BL: How many women have osteoporosis? J Bone Miner Res 1992;7:10051010.

-4 D’Amelio P, Grimaldi A, Di Bella S, Brianza $S$, et al: Estrogen deficiency increases osteoclastogenesis up-regulating T cells activity: a key mechanism in osteoporosis. Bone 2008; 43:92-100.

5 Hadjiargyrou M, Mcleod K, Ryaby JP, Rubin C: Enhancement of fracture healing by low intensity ultrasound. Clin Orthop Relat Res 1998;355:S216-S229.

6 Duarte LR: The stimulation of bone growth by ultrasound. Arch Orthop Trauma Surg 1983;101:153-159.
Kousteni S, Bellido T, Plotkin LI, O’Brien CA, Bodenner DL, et al: Nongenotropic, sexnonspecific signaling through the estrogen or androgen receptors: dissociation from transcriptional activity. Cell 2001;104:719730.

-8 Anderson DM, Maraskovsky E, Billingsley WL, Dougall WC, Tometsko ME, Roux ER, Teepe MC, DuBose RF, Cosman D, Galibert L: A homologue of the TNF receptor and its ligand enhance T-cell growth and dendriticcell function. Nature 1997;390:175-179.

-9 Schortinghuis J, Bronckers A, Stegenga B, Raghoebar G, de Bont L: Ultrasound to stimulate early bone formation in a distraction gap: a double blind randomised clinical pilot trial in the edentulous mandible. Arch Oral Biol 2005;50:411-420.

10 Pilla AA, Mont MA, Nasser PR, et al: Noninvasive low-intensity pulsed ultrasound accelerates bone healing in the rabbit. J Orthop Trauma 1990;4:246-253.

11 Ott SM: Osteoporosis in women with spinal cord injuries. Phys Med Rehabil Clin N Am 2001;12:111-131.
12 Warden SJ, Bennell KL, Matthews B, Brown DJ, McMeeken JM, Wark JD: Efficacy of lowintensity pulsed ultrasound in the prevention of osteoporosis following spinal cord injury. Bone 2001;29:431-436.

13 Lirani APR, Lazaretti-Castro M: Evidences of physical agents action on bone metabolism and their potential clinical use (in Portuguese). Arq Bras Endocrinol Metabol 2005; 49:891-896

14 Warden SJ, Favaloro JM, Bennell KL, McMeeken JM, Ng KW, Zajac JD, Wark JD: Low-intensity pulsed ultrasound stimulates a bone-forming response in UMR-106 cells. Biochem Biophys Res Commun 2001;286: 443-450.

15 Saito M, Soshi S, Tanaka T, Fujii K: Intensityrelated differences in collagen post-translational modification in MC3T3-E1 osteoblasts after exposure to low- and highintensity pulsed ultrasound. Bone 2004;35: 644-655. 
-16 Mukai S, Ito H, Nakagawa Y, Akiyama H, Miyamoto M, Nakamura T: Transforming growth factor- $\beta_{1}$ mediates the effects of lowintensity pulsed ultrasound in chondrocytes. Ultrasound Med Biol 2005;31:17131721.

$>17$ Claes L, Willie B: The enhancement of bone regeneration by ultrasound. Prog Biophys Mol Biol 2007;93:384-398.

-18 Pounder NM, Harrison AJ: Low intensity pulsed ultrasound for fracture healing: a review of the clinical evidence and the associated biological mechanism of action. Ultrasonics 2008;48:330-338.

-19 Sena K, Leven RM, Mazhar K, Sumner DR, Virdi AS: Early gene response to low-intensity pulsed ultrasound in rat osteoblastic cells. Ultrasound Med Biol 2005;31:703708.

-20 Park BW, Hah YS, Kim DR, Kim JR, Byun $\mathrm{JH}$ : Osteogenic phenotypes and mineralization of cultured human periosteal-derived cells. Arch Oral Biol 2007;52:983-989.

-21 Declercq HA, Verbeeck RMH, De Ridder LI, Schacht EH, Cornelissen MJ: Calcification as an indicator of osteoinductive capacity of biomaterials in osteoblastic cell cultures. Biomaterials 2005;26:4964-4974.

-22 Igarashi M, Kamiya N, Hasegawa M, Kasuya T, Takahashi T, Takagi M: Inductive effects of dexamethasone on the gene expression of Cbf $\alpha 1$, osterix and bone matrix proteins during differentiation of cultured primary rat osteoblasts. J Mol Histol 2004;35:3-10.

$\checkmark 23$ Chien HH, Lin WL, Cho MI: Interleukin1beta-induced release of matrix proteins into culture media causes inhibition of mineralization of nodules formed by periodontal ligament cells in vitro. Calcif Tissue Int 1999; 64:402-413.
24 Beck GR Jr, Sullivan EC, Moran E, Zerler B: Relationship between alkaline phosphatase levels, osteopontin expression, and mineralization in differentiating MC3T3-E1 osteoblasts. J Cell Biochem 1998;68:269-280.

25 Stein GS, Lian JB, Owen TA: Relationship of cell growth to the regulation of tissue-specific gene expression during osteoblast differentiation. FASEB J 1990;4:3111-3123.

26 Medlock KL, Lyttle CR, Kelepouris N, Newman ED, Sheehan DM: Estradiol down-regulation of the rat uterine estrogen receptor. Proc Soc Exp Biol Med 1991;166:293-300.

27 Warden SJ, Bennell KL, Forwood MR, McMeeken JM, Wark JD: Skeletal effects of lowintensity pulsed ultrasound on the ovariectomized rodent. Ultrasound Med Biol 2001; 27:989-998.

-28 Xiao G, Jiang D, Ge C, Zhao Z, Lai Y, Boules H, Phimphilai M, Yang X, Karsenty G, Franceschi RT: Cooperative interactions between activating transcription factor 4 and Runx 2 / Cbfa1 stimulate osteoblast-specific osteocalcin gene expression. J Biol Chem 2005;280 30689-30696.

29 Liu W, Toyosawa S, Furuichi T, Kanatani N, Yoshida C, Liu Y, Himeno M, Narai S, Yamaguchi A, Komori T: Overexpression of Cbfa1 in osteoblasts inhibits osteoblast maturation and causes osteopenia with multiple fractures. J Cell Biol 2001;155:157-166.

30 Rubin CT, Hausman MR: The cellular basis of Wolff's law. Transduction of physical stimuli to skeletal adaptation. Rheum Dis Clin North Am 1988;14:503-517.

31 Anglen J: The clinical use of bone stimulators. J South Orthop Assoc 2003;12:46-54.
32 Cowin SC, Moss-Salentijn L, Moss ML: Candidates for the mechanosensory system in bone. J Biomech Eng 1991;113:191-197.

33 Yuge L, Okubo A, Miyashita T, Kumagai T, Nikawa T, Takeda S, Kanno M, Urabe Y, Sugiyama M, Kataoka K: Physical stress by magnetic force accelerates differentiation of human osteoblasts. Biochem Biophys Res Commun 2003;311:32-38.

34 Naruse K, Sokabe M: Involvement of stretchactivated ion channels in $\mathrm{Ca}^{2+}$ mobilization to mechanical stretch in endothelial cells. Am J Physiol 1993;264:1037-1044.

35 Kiseleva I, Kamkin A, Kohl P, Lab MJ: Calcium and mechanically induced potentials in fibroblasts of rat atrium. Cardiovasc Res 1996;32:98-111.

36 Shen J, Gimbrone MA Jr, Luscinskas FW, Dewey CF Jr: Regulation of adenine nucleotide concentration at endothelium-fluid interface by viscous shear flow. Biophys J 1993; 64:1323-1330.

37 Kato T, Ishiguro N, Iwata H, Kojima T, Ito T, Naruse K: Up-regulation of COX 2 expression by uni-axial cyclic stretch in human lung fibroblast cells. Biochem Biophys Res Commun 1998;224:615-619.

38 Oxlund BS, Ortoft G, Andreassen TT, Oxlund $\mathrm{H}$ : Low-intensity, high-frequency vibration appears to prevent the decrease in strength of the femur and tibia associated with ovariectomy of adult rats. Bone 2003; 32:69-77.

39 Flieger J, Karachalios T, Khaldi L, Raptou P, Lyritis G: Mechanical stimulation in the form of vibration prevents postmenopausal bone loss in ovariectomized rats. Calcif Tissue Int 1998;63:510-514. 